\section{An analysis of the nonmatching components of the stimulus matching paradigm*}

\author{
STANLEY G. SMITH \\ The University of Mississippi, University, Miss. 38677 \\ and \\ RICHARD M. MALO'T $\dagger, \dagger \dagger$ \\ Western Michigan University, Kalamazoo, Mich. 49001
}

Two pigeons were trained on a simultaneous split-field single-key stimulus-matching procedure. The decline of keypecking during nonmatching stimuli was examined. Observations during nonmatching conditions indicated that as keypecking declined discrete overt patterns of behavior emerged to each of the two nonmatching compounds. The decline in keypecking and the emergence of discrete overt patterns of behavior was observed to occur first to one nonmatching compound and then to the second combination.

The analysis of matching behavior which occurs during the procedure of simultaneous matching to sample or simultaneous sameness-difference has had an extensive history of research, e.g., Kluver, 1933; Weinstein, 1941; Nissen, Blum, \& Blum, 1947; Robinson, 1955; Ginsburg, 1957; Cumming \& Berryman, 1965. However, little research has been attempted using successive matching procedures for the analysis of behavior (Kelleher, 1958; Honig, 1965; Cohen, 1969). The neglect of the successive matching paradigm seems somewhat tragic for two reasons: (1) Separate presentations of both the matching and nonmatching stimulus compounds are possible with this procedure; (2) separate stimulus presentation allows discrete and unconfounded behavioral analysis in the presence of a single stimulus condition.

More specifically, during the simultaneous procedure the development of powerful approach behaviors may obscure or mask the occurrence of other behaviors which were emitted in the presence of nonmatching conditions. With discrete matching and nonmatching presentations, behaviors which occur during the nonmatching conditions could be separately examined.

A successive matching procedure which provided discrete presentations

* This research was supported by Public Health Service Grant MH13178-01, Richard W. Malott, principal investigator. The preparation of this manuscript was supported in part by AFOSR Contract No. F44620-69-C-0050, awarded to William F. Crowder, University of Mississippi.

+Now at Biocontrol systems Laboratory, University of Mississippi. University, Mississippi 38677 .

t+The authors wish to thank John Bedford, Robert Haney, and W. M. Smith for their editorial assistance. of the different stimulus conditions was devised by Malott \& Malott (1967). The Malott and Malott procedure allows split-field illumination, thus the capacity for successive stimulus matching.

The present study was designed, using the Malott and Malott technique, to examine the possibility that behaviors might be occurring during the nonmatching condition which were not previously reported in the successive or simultaneous matching literature.

Two experimentally naive White Carneaux pigeons were used as Ss. All Ss were maintained at $75 \%$ of free-feeding weight, $\pm 15 \mathrm{~g}$. Water and grit were available ad lib in the S's home cage. Purina pigeon grain was used as daily food and as the reinforcer.

\section{APPARATUS}

The experimental chamber was a standard Lehigh Valley Electronics pigeon chamber. The right side panel of the chamber contained the food magazine and one 24-mm plastic response key. Split-field stimuli were rear projected by a single plane readout and Industrial Electronics Engineer's Series 10-8039-1815L. The split-field projection consisted of a $3-\mathrm{mm}$-wide vertical black stripe running down the midline of the single plane readout's projection surface, with independent illumination of either the right or left halves of the display. The four stimulus conditions used were: red-red (R-R) or green-green (G-G), the matching compounds; and red-green (R-G) or green-red (G-R), the nonmatching compounds. The hyphen (-) between compounds mentioned above signifies the position of the stimulus, e.g., R-G indicates that red appeared on the left

\section{SUBJECTS}

with green on the right. One $7-W$ incandescent light was used for ambient illumination of the experimental chamber. Data were recorded from observations of the $E$ and from electromechanical counters. PROCEDURE

After the initial shaping was completed, stimulus matching procedures were instituted. Each trial was started with a 10 -sec ITI. At the termination of the ITI, one of the matching conditions (R-R or G-G) or one of the nonmatching conditions (R-G or G-R) was presented. A keypeck during the matching stimuli produced $3 \mathrm{sec}$ access to grain and was followed by the next ITI. Keypecks during the nonmatching stimuli produced a 10-sec time-out (TO), which was followed by the next ITI. The TO procedure consisted of a complete blackout of the experimental chamber. Presentations of nonmatching stimuli were terminated after $5 \mathrm{sec}$ if no response occurred, and the next ITI was started.

An experimental session was defined as 100 random stimulus presentations. Each combination (i.e., R-R, G-G, R-G, and G-R) was presented 25 times. The criterion for learning was set at 40 or more trials where no response occurred during the nonmatching stimuli in a single session. The criterion of no response during discrete nonmatching stimuli was set at 20 or more trials of no response in a single session.

RESULTS AND DISCUSSION

Data on the drop out of keypecks during the nonmatching stimuli are presented in Fig. 1. As can be seen, the criterion of no responses in the presence of the nonmatching stimuli was met by both Ss on or before the 25 th session. An analysis of keypecking behavior during the discrete nonmatching compounds is shown in Fig. 2. The data indicate that responding to the discrete nonmatching components dropped out first during one of the two stimulus conditions, followed by a decrease during the other. For Bird 1, the first nonmatching condition during which key pecks declined to the criterion of 20 trials of nonresponse was R-G (Session 22), followed by G-R (Session 25). Bird 2's keypecking behavior dropped out first during G-R (Session 14) and then during R-G (Session 18).

Observational data indicated that the decline of responses on the key during discrete nonmatching compounds was correlated with the development of mediating behavior patterns. Bird 1 exhibited a short movement to the left and pecked on the intelligence panel near the key (i.e., off to the side of the key) during 


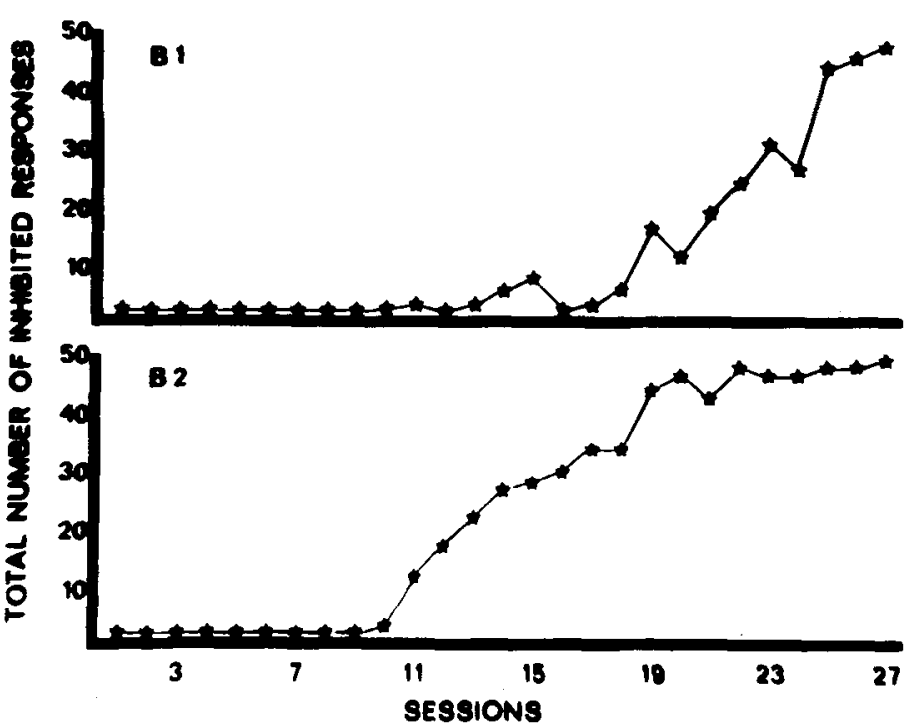

Fig. 1. Number of $\mathrm{S}-$ trials with no response as a function of sessions.


Fig. 2. Acquisition of the discrete nonmatching stimulus conditions. the $R-G$ condition, while a movement to the right and pecks near the key mediated nonresponding to the G-R stimulus compound. Bird 2 initiated a 360 -deg turn to the right in the presence of the R-G compound, while a 360-deg turn to the left mediated the G-R condition. It was also observed that superstitious responding in the air near the key occurred during the ITI with both birds. Behavior exhibited in the presence of the blank key (ITI) and the nonmatching compounds (R-G and G-R) seemed to hold the following in common: (1) It initially developed from some random pattern of behavior which accidentally mediated the no-response contingencies; and (2) after a period of acquisition, fixed patterns of mediating behavior emerged to all three stimulus conditions (i.e., blank key, R-G, and G-R).

The present observation of behavior patterns which mediated some temporal contingency is not the first to be reported. For example, Hunter (1913), Fletcher (1964), and Miles (1957) have noted gross body orientations with which animals bridged the delay interval in the delayed-response problem. Also, research on temporally defined schedules (e.g., Hodos, Ross, \& Brady, 1962; Laties, Weiss, \& Weiss, 1969; Nevin \& Berryman, 1963) has shown that mediating behavior emitted by the $\mathrm{S}$ between responses on a lever may adventitiously determine response distributions. Further, Blough (1959) noted discrete mediating behaviors during a delayed matching-to-sample problem. Two discrete mediating chains appeared, each chain associated with one of the two sample conditions. According to Blough, these seem to control the correctness of the choice response, Thus, though descriptions of mediating behaviors occurring during some temporal contingency associated with positive reinforcement have previously been reported, those occurring during nonmatching conditions have not. However, a number of earlier articles are relevant to the discussion of the present results. Spence (1952) took the position that, during complex discrimination learning, both approach and avoidance responses are acquired. The results of the present study seem to indicate that the mediating behaviors were avoidance responses. More specifically, the emission of the mediating behavior by the $\mathrm{S}$ prevented the occurrence of the aversive time-out interval. Thus, the present finding would seem to support the avoidance half of Spence's position. Nissen (1953), in his theory of "transverse patterning," makes the point that organisms learn two types of content during matching training: identity and difference. The present work, which primarily analyzed differences, indicated that, at least during the acquisition stages, the Ss learn differences within differences. If mere "identical peck" vs "different don't peck" discriminations were involved, the two discrete patterns of behavior, one for each nonmatching condition, would more than likely not have emerged. Thus, differences within differences in Nissen's terms were also learned. Also, Harlow's (1957) work with error factors during conditional discriminations could be extended to imply that learning which occurs to the nonmatching condition would be important to the acquisition of the matching behavior. The present research produced correlational data which seem to indicate that the development of mediating behaviors was important for the dropping out of keypecking. This was observed when a student accidentally disturbed the $S$ (B-1) as it started the emission of a mediating pattern of behavior. The bird stopped the mediating behavior, then began responding with keypecks to both matching and nonmatching conditions. Two sessions later, mediating patterns of behavior were again emitted during the nonmatching conditions on particular trials during which responding on the key did not occur, strongly suggesting that the behavior patterns observed provide discriminative stimuli for a correct response. And, if the correlational evidence was correct, the behavior patterns also control the probability of a correct response. Thus they are not "superstitious" in nature. For superstitious behavior, by definition, does not control the correctness of a response, but is incidental to the experimentally defined response.

In conclusion, it would seem from these data that to measure only inhibition of responses to the key precludes a more complete behavioral picture of what was occurring in the experimental chamber. Certainly, the electromechanical response counters indicated that pecking behavior was dropping out during nonmatching conditions, but the observational data proved to be far more revealing. Future research might consider the use 
of more human Os and/or provide some type of recordable mediating response, e.g., a number of other keys which light up during the nonresponse conditions.

\section{REFERENCES}

BLOUGH, D. S. Delayed matching in the pigeon. Journal of the Experimental Analysis of Behavior, 1959,2,151-160 COHEN, L. Generalization during acquisition, extinction, and transfer of matching with an adjustable comparison Journal of the Experimental Analysis of Behavior, 1969, 12, 463-474.

CUMMING, $W$. \&ERRYMAN, R. Thè complex discriminated operant: Studies of matching-to-sample and related problems.

generalization. Stanford, Calif: Stanford University Press, 1965. Pp. 284-330.

FLETCHER, H. J. Activity during delay interval and delayed response errors in monkeys. Psychological Reports, 1964, 14.685-686

GINSBURG, $N$. Matching in pigeons. Journal of Comparative \& Physiological Psychology, 1957, 50, 261-263.

HARLOW, H. F. Learning set and error factor theory. In S. Koch (Ed.). Psychology: A study of a science. New York: McGraw-Hill, 1959. Pp. 492-537.

HODOS, W., ROSS, G. S., \& BRADY, J.V. Complex response patterns during temporally spaced responding. Joumal of the Experimental Analysis of Behavior. $1962,5,473-479$.

HONIG, W. Discrimination, generalization and transfer on the basis of stimulus difference. In D. J. Mostofsky (Ed.). Stimulus generalization. Stanford, Calif: Stanford University Press, 1965. Pp. 218-254

HUNTER, $W$. $S$. The delayed reaction in animals and children. Behavior
Monographs, 1913, 2, No. 1 (Serial No. 6).

KELLEHER, R. Concept formation in champanzees. Science, 1958,128 , 777-778.

KLUVER, H. Behavior mechanisms in monkeys. Chicago: University of Chicago Press, 1933.

LATIES, V. G., WEISS, B., \& WEISS, A. B. Further observations on overt "mediating" behavior and the discrimination of time. Journal of the Experimental Analysis of Behavior, 1969. $12,43-57$.

MALOTT, R., \& MALOTT, K. An analysis of stimulus matching in terms of stimulus generalization. Paper read at American Psychological Association meeting. New York, 1967

MILES, $R$. C. Delayed-response learning in the marmoset and the macaque. Joumal of Comparative \& Physiological Psychology, 1957, 50, 352-355.

NEVIN, J. A., \& BERRYMAN, R. A note on chaining and temporal discrimination. Journal of the Experimental Analysis of Behavior, 1963, 6, 109-113.

NISSEN, H. W. Sensory patterning versus central organization. Joumal of Psychology, 1953, 36, 271-287.

NISSEN, H., BLUM, J., \& BLUM, $R$. Analysis of matching behavior in chimpanzee. Journal of Comparative \& Physiological Psychology, 1948, 41, 62-74.

ROBINSON, J. The sameness-difference discrimination problem in chimpanzee. Journal of Comparative \& Physiological Psychology, 1955, 48, 195-197.

SPENCE, $K$. W. The nature of the response in discrimination learning. Psychological Review, 1952, 59, 89-93.

WEINSTEIN, B. Matching-from-sample by rhesus monkeys and by children. Journa of Comparative \& Physiological Psychology, 1941, 31, 195-213.

\section{Primary stimulus generalization effect in latent extinction of latent acquisition}

\author{
RICHARD L. PATTEN and REGINALD L. HENDRICKS \\ Iowa State University, Ames, Iowa 50010
}

After latent acquisition training placements to reward in the goalbox of a straight runway, Ss received latent extinction training placements to nonreward in either the runway goalbox or a distinctive goalbox. Control groups received either latent acquisition training only or neither type of training. Running speed data from a single test trial provided evidence for the operation of primary stimulus generalization in producing latent acquisition and latent extinction effects.

A current analysis of the empirical law of appetitive reinforcement is the incentive motivation-conditioning model formulated by Spence (1956), Sheffield (1966), and others. According to this approach, food at the end of a response sequence, e.g., in the goalbox (GB) of a runway, leads to the conditioning of a motivational response to $\mathrm{GB}$ cues. Locomotion in the runway is facilitated when, via primary stimulus generalization (runway-GB similarity), and/or secondary (acquired) stimulus generalization, the implicit

* The basic elements of this critique were developed by $R$. Patten and Roy Matsumoto in a paper presented to Dr. Spence's learning-theory seminar, University of Iowa, 1965. motivational response $(\mathrm{rg})$ occurs in the runway. Several early tests of the primary stimulus generalization aspect of the theory (e.g., Stein, 1957) employed a placement technique, where Ss were given direct placements to food in the GB and then one or more test trials in the runway, with evidence for the primary stimulus generalization (PSG) of $\mathrm{rg}$ being sought in facilitation of runway locomotion on the test trial(s). This "latent acquisition" effect is now reliably obtained (Patten, 1968). An analogous "latent extinction" (LE) effect (where performance of a previously rewarded response is decreased on test trials following direct placement to nonreward in the GB) was interpreted by Moltz (1957) as possibly due to the extinction of association between $\mathrm{rg}$ and GB cues during the direct placements.

Experiments by Hughes, Davis, \& Grice (1960) and Koppman \& Grice (1963), which tested the PSG aspect of the rg account of latent extinction by manipulating runway-GB similarity during LE placements, are repeatedly cited (e.g., Donahoe, 1970; Bolles \& Grossen, 1970) as failing to support $\mathrm{rg}$ theory. However, these studies involve a serious source of confounding* and must be redone free of the confounding: In both studies, Ss were given eight noncorrection learning trials per day for 3 days on position discrimination in a T-maze, with runs to the reward arm $\left(\mathrm{S}^{+}\right)$and the nonreward arm $(S-)$ equated by a forcing procedure. Half of the Ss had as $\mathrm{S}^{+}$the right-side $\mathrm{GB}$, which was different (in size, shape, and brightness, or simply in brightness) from the rest of the gray apparatus. Half had as $\mathrm{S}+$ the nondistinctive left-side GB, which was merely an extension of the runway. Half of each group received LE placements in S+, with the other half used as a no-treatment control. On each of 4 days, four LE placements were followed by a nonreward maze test trial, with four discrimination retraining trials following the test trial on the first 3 days. Contrary to the apparent prediction from the PSG aspect of rg theory, maze traversal speeds on test trials did not indicate greater $L E$ effect in $S$ s receiving $L E$ in the nondistinctive GB (Group E-ND) than in $S s$ receiving $L E$ in the distinctive GB (Group E-D).

Consider the possibility that "competing responses" occurring in the GB on $\mathrm{S}$ - trials become associated with S- cues (Spence, 1956), or that a frustration reaction (Amsel, 1958) becomes conditioned to S- GB cues on these trials. Also consider that high runway-S+ GB similarity is associated with low runway-S- GB similarity, and low runway-S+ GB similarity is associated with high runway-S- GB similarity in these groups; for this reason, $\mathrm{S}-$ effects would be stronger in the runway for Group E-D Ss than for Group E-ND Ss. Thus, although the alley locomotion of Group E-ND Ss may have been interfered with the most by LE effects, the alley locomotion of Group E-D Ss may have been interfered with most by $\mathrm{S}$ effects, preventing the detection of differential $L E$ effects when the two groups were compared. Evidence for strong $\mathrm{S}-$ effects in both studies is suggested by the finding that, in both studies combined, only four choices of the $\mathrm{S}-$ arm occurred in 320 test trials. The present investigation avoided confounding between PSG of $\mathrm{S}-$ cues 